\title{
P06-09. Web based interviewing system for HIV-behavior research in the settings of vaccine and non vaccine prevention trials
} JE Peinado*, JL Sanchez and JR Lama

\author{
Address: Biostatistics Data Management and Informatics (BIDS), INMENSA, Lima, Peru
}

* Corresponding author

from AIDS Vaccine 2009

Paris, France. 19-22 October 2009

Published: 22 October 2009

Retrovirology 2009, 6(Suppl 3):P98 doi:10.1 I86/1742-4690-6-S3-P98

This abstract is available from: http://www.retrovirology.com/content/6/S3/P98

(c) 2009 Peinado et al; licensee BioMed Central Ltd.

\section{Background}

Novel and innovative health informatics strategies have shown to help in HIV-behavior research. As a first step to build novel informatics tools for clinical trials research at developing countries, we developed a computer assisted self interviewing (CASI) application, that was validated by the U.S. NIH and manages with straightforward efficiency sexual behavior data from men who have sex with men (MSM) participating in HIV prevention studies.

\section{Methods}

During 2004, Biostatistics Data Management and Informatics Unit from Peruvian Clinical Trials Unit (CTU) developed a fully featured web CASI named SISQUAL, that permits to create and deploy questionnaires ranging from standard scroll-down forms to those with complex skipping, advanced list handling, multi-lingual interviewing, piping, and online and offline data viewing. It was built following data management principles and CRF21 part 11 security features.

\section{Results}

More than 7,700 MSM has completed semi-structured interviews that included topics on their sexual identification, sexual behavior, and their experiences with condom, alcohol and drugs having sex with their partners. CASI, translated in 8 languages (Spanish, English, Portuguese, Thai, Sesotho, Afrikaans, Xhosa, and Zulu), provides web data collection, auditing, and integration by providing automatic quality control checking, branching and skipping questions collecting data for the Peruvian HIV and STD third generation sentinel surveillance in 2006 and
2008 (Arequipa, Ica, Iquitos, Lima, Sullana, and Pucallpa) and international sites (Cape Town, Chennai, Guayaquil, Johannesburg, New York, Rio Janeiro, San Francisco, Sao Paulo, and Seattle) for U.S. NIH funded trials.

\section{Conclusion}

An innovative fully featured web based CASI developed for the Peruvian CTU collects sexual behavior data with straightforward efficiency as a first step to increase clinical trial site capacity for challenging AIDS vaccine research agenda. 